\title{
Soil carbon stocks and their variability across the forests, shrublands and grasslands of peninsular Spain
}

\author{
E. Doblas-Miranda ${ }^{1}$, P. Rovira ${ }^{2}$, L. Brotons ${ }^{1,2}$, J. Martínez-Vilalta ${ }^{1,3}$, J. Retana ${ }^{1,3}$, M. Pla ${ }^{2}$, and J. Vayreda ${ }^{1}$ \\ ${ }^{1}$ CREAF, Cerdanyola del Vallès 08193, Spain \\ ${ }^{2}$ Forest Sciences Center of Catalonia (CTFC), St. Llorenç de Morunys km 2, 25280 Solsona, Spain \\ ${ }^{3}$ University Autònoma Barcelona, Cerdanyola del Vallès 08193, Spain
}

Correspondence to: E. Doblas-Miranda (e.doblas@creaf.uab.es)

Received: 6 May 2013 - Published in Biogeosciences Discuss.: 4 July 2013

Revised: 4 November 2013 - Accepted: 19 November 2013 - Published: 18 December 2013

\begin{abstract}
Accurate estimates of $\mathrm{C}$ stocks and fluxes of soil organic carbon (SOC) are needed to assess the impact of climate and land use change on soil $\mathrm{C}$ uptake and soil $\mathrm{C}$ emissions to the atmosphere. Here, we present an assessment of SOC stocks in forests, shrublands and grasslands of peninsular Spain based on field measurements in more than 900 soil profiles. SOC to a depth of $1 \mathrm{~m}$ was modelled as a function of vegetation cover, mean annual temperature, total annual precipitation, elevation and the interaction between temperature and elevation, while latitude and longitude were used to model the correlation structure of the errors. The resulting statistical model was used to estimate SOC in the $\sim 8$ million pixels of the Spanish Forest Map $\left(29.3 \times 10^{6}\right.$ ha $)$. We present what we believe is the most reliable estimation of current SOC in forests, shrublands and grasslands of peninsular Spain thus far, based on the use of spatial modelling, the high number of profiles and the validity and refinement of the data layers employed. Mean concentration of SOC was $8.7 \mathrm{~kg} \mathrm{~m}^{-2}$, ranging from $2.3 \mathrm{~kg} \mathrm{~m}^{-2}$ in dry Mediterranean areas to $20.4 \mathrm{~kg} \mathrm{~m}^{-2}$ in wetter northern locations. This value corresponds to a total stock of $2.544 \mathrm{Tg}$ SOC, which is four times the amount of $\mathrm{C}$ estimated to be stored in the biomass of Spanish forests. Climate and vegetation cover were the main variables influencing SOC, with important ecological implications for peninsular Spanish ecosystems in the face of global change. The fact that SOC was positively related to annual precipitation and negatively related to mean annual temperature suggests that future climate change predictions of increased temperature and reduced precipitation may strongly reduce the potential of Spanish soils as $\mathrm{C}$ sinks. However, this may be mediated by changes in vegetation
\end{abstract}

cover (e.g. by favouring the development of forests associated to higher SOC values) and exacerbated by perturbations such as fire. The estimations presented here provide a baseline to estimate future changes in soil $\mathrm{C}$ stocks and to assess their vulnerability to key global change drivers, and should inform future actions aimed at the conservation and management of $\mathrm{C}$ stocks.

\section{Introduction}

It is widely accepted that the effects of global warming could be offset by the reduction of carbon (C) emissions and the protection and increase of $\mathrm{C}$ stocks worldwide (Solomon et al., 2007). Therefore, concerned nations need to assess their stocks and fluxes of $\mathrm{C}$, including soil organic carbon (SOC) estimates (Bell and Worrall, 2009). The amount of $\mathrm{C}$ in the world's soils represents a large reservoir of about 1.500 1.600 Pg C (Batjes, 1996; Eswaran et al., 1993). Soils play a crucial role in the global $\mathrm{C}$ cycle by storing 300 times the annual amount of released $\mathrm{C}$ from fossil fuel burning (Schulze and Freibauer, 2005). However, this storage capacity is dynamic and depends on land use changes, land management and environmental changes (Schlesinger, 1995). Studies with accurate assessments of SOC stocks at the country level are critical. These SOC stocks are the necessary baseline for research on the impact of land use change and climate change on SOC stocks dynamics, and therefore on soil $\mathrm{C}$ behaviour and soil $\mathrm{C}$ emissions to the atmosphere (Adger and Brown, 1994; Chaplot et al., 2009). 
Estimations and studies about SOC at regional and national scales are still scarce and methodologies vary among them (Martin et al., 2011). SOC stocks have been estimated by assigning mean SOC values to soil types or land covers and applying them to large scales (e.g. Rodríguez-Murillo, 2001; Chiti et al., 2012; Coomes et al., 2002; Zhou et al., 2003). However, such assessments do not consider the large variation in SOC within a soil or cover type (Liebens and VanMolle, 2003; Davis et al., 2004). Certain studies thus claim that soil series or land use mean values are not sufficient to correctly assess SOC, and factors such as climate, topography or land management practices should be also considered in the estimations (Krishnan et al., 2007; Bell and Worrall, 2009; Zhang et al., 2011). Spatial modelling approaches can improve SOC stock estimations, taking into account these factors by projecting to all the studied region statistical associations the real measurements of SOC in the same area. Such approaches should provide a continuous and accurate map for the whole study area (Razakamanarivo et al., 2011; Zhang et al., 2011; Wiesmeier et al., 2011).

Several variables controlling the spatial distribution of SOC have been identified, including soil type, soil texture, geological substrate, rainfall, temperature, moisture, land cover, historical land use, altitude, slope and management practices (Powers and Schlesinger, 2002; Mueller and Pierce, 2003; Krishnan et al., 2007; Schulp and Veldkamp, 2008; Zhang et al., 2011). From broad studies at the Mediterranean scale to more local studies of Spanish soils, climate and land use are considered the most important factors (RodríguezMurillo, 2001; Hontoria et al., 2005; Baritz et al., 2010; Rodeghiero et al., 2011).

The Iberian Peninsula presents a characteristic spatial and temporal variability based upon a diverse geography and a variety of Atlantic and Mediterranean climates. This heterogeneous landscape offers a natural laboratory to understand the factors affecting SOC, while assessing overall country stocks. Here we use field measures of more than 900 soil profiles on forests, shrublands and grasslands of peninsular Spain to build a statistical model of SOC stocks, taking into consideration vegetation cover, climate, soil characteristics, slope and elevation as potential explanatory variables. The main objectives of the study are (a) to obtain an accurate assessment of SOC stocks of forests, shrublands and grasslands in Spain and compare these results with previous national and regional estimates; and (b) to assess the effects of the main controlling factors of the spatial distribution of SOC, and relate them to the effects of predicted climate and land use changes in the Iberian Peninsula.

\section{Materials and methods}

\subsection{Study site}

The study area comprises peninsular Spain (excluding the Canary and Balearic islands) forests, shrublands and pastures, for a total surface of 24.3 million ha. Croplands were not included in the analyses because their SOC responds to different variables compared to forests, shrublands and grasslands, such as the type of cultivation and the organic matter inputs (Romanyà et al., 2007). The Mediterranean climatic domain, characterized by mild winters and hot and dry summers, covers almost all peninsular Spain except the northwest, represented by the wet and cold temperateoceanic climatic domain (Capel Molina, 2000). Most soils in the area are typically Mediterranean Cambisols, occurring in the eastern half and on the southern and northern coasts of Spain. Leptosols appear in most mountainous systems, and Regosols are also present in wide areas of the western half of the country. Finally, Luvisols, in the northern part of the Inner Plateau, and Calcisols, in the Ebro and Segura valleys, are also well represented (FAO/IIASA/ISRIC/ISSCAS/JRC, 2012). According to the Spanish Forest Map (Área de Banco de Datos de la Naturaleza; http://www.magrama. gob.es/es/biodiversidad/servicios/banco-datos-naturaleza/ informacion-disponible/mfe50_descargas_ccaa.aspx), the seven most abundant tree species are Quercus ilex, Pinus halepensis, $P$. pinaster, $P$. sylvestris, $P$. nigra, $Q$. pyrenaica and Fagus sylvatica.

\subsection{Soil profiles}

Information was compiled from the literature (Supplement). Literature search was conducted through a systematic reviewing of Spanish soil science journals (particularly "Anales de Edafología y Agrobiología", but also journals published by the CSIC, the Spanish Council for Scientific Research), Ph.D. theses, reports of meetings of the Spanish Society of Soil Science, and other similar publications. The initial data set included nearly 2000 profiles established in non-crop areas of Spain from 1975 to 2007. SOC was estimated in $\mathrm{kg} \mathrm{m}^{-2}$ to a maximum depth of $1 \mathrm{~m}$ (considering that approximately $75 \%$ of the total SOC stock occurs in the first m depth; Olsson, 2002).

The total amount of $\mathrm{C}$ of the $i$ horizon $\left(C_{i}\right.$, in $\left.\mathrm{g} \mathrm{m}^{-2}\right)$ is given by

$C_{i}=D_{\mathrm{b}} \cdot \frac{C}{100} \cdot 10000 \cdot T \cdot \frac{100-V}{100}$,

where $D_{\mathrm{b}}$ is the bulk density $\left(\mathrm{g} \mathrm{cm}^{-3}\right), C$ the concentration of organic C (in \%), $T$ the thickness of the horizon (in $\mathrm{cm}$ ) and $V$ the percent of the total volume occupied by stones and gravel. 
From the total $\mathrm{C}$ in the horizons, the total $\mathrm{C}$ in the soil profile down to $1 \mathrm{~m}$ was calculated as

$\mathrm{C}=\left(\sum_{i=1}^{n} C_{i}\right)+C_{n+1} \frac{100-u L_{n+1}}{T_{n+1}}$,

where $C_{i}$ is the total amount of $\mathrm{C}$ in the horizons (from 1 to $n$ ) whose lower limit is not deeper than $100 \mathrm{~cm}, C_{n+1}$ is the total amount of $\mathrm{C}$ in the deeper horizon (if described) whose lower limit is deeper than $100 \mathrm{~cm}, T_{n+1}$ the total thickness of this horizon, and $u L_{n+1}$ its upper limit. This deeper horizon $(n+1)$ was included in the calculation only if its upper limit was $<100 \mathrm{~cm}$ deep; it was not included if its upper limit was exactly $100 \mathrm{~cm}$, or deeper.

When the limits of the profile were not indicated, we gave the deeper horizon a standard thickness of $20 \mathrm{~cm}$. When the deepest horizons were not analyzed, \% $\mathrm{C}$ was estimated by curve-fitting techniques, mostly standard exponential curves (either single or double) and polynomial curves in some cases. From the profiles where experimental numeric data about bulk density was available, we derived empirical relationships to estimate bulk density from total OC in the horizon and (when available) clay content and applied them to the profiles for which bulk density was unknown (e.g. Rodríguez-Murillo, 2001).

Stoniness was obtained from the following equation (Cabidoche, 1979):

$V=\frac{R}{D_{R}} \frac{100}{\frac{R}{D_{R}}+\frac{100-R}{D_{\mathrm{b}}}}$,

where $R$ is the weight of coarse materials (gravel and stones), as $\%$ of total weight of the horizon, $D_{R}$ their density (which depended on the kind of parent material), and $D_{\mathrm{b}}$ the bulk density of the horizon. Any visual estimation of stones and gravel abundance was translated to a percentage of volume occupied by stones, ranging from 0 to $75 \%$. When no information about the abundance of blocks, stones or gravel was found, we applied the mean $V$ value obtained for profiles over the same type of parent material from which stoniness was available.

Litter layers were not measured in most profiles and therefore were not included in the analyses. It should be noted, however, that this layer comprises a small percent of the total SOC amount (for example, only $2.6 \%$ of total SOC for an assessment of Mediterranean soils; Rodeghiero et al., 2011).

Every profile also contained information about land use, parental material, soil texture and consistency, elevation and slope, as described in the original publication and geographical coordinates with a resolution of $1^{\circ}$. Of all the profiles in the initial data set, $37 \%$ were excluded due to missing data on one or more of the explanatory variables used to model SOC. The spatial resolution implied that sometimes we had more than one soil profile per coordinate. In these cases we selected the profile for which the vegetation cover reported

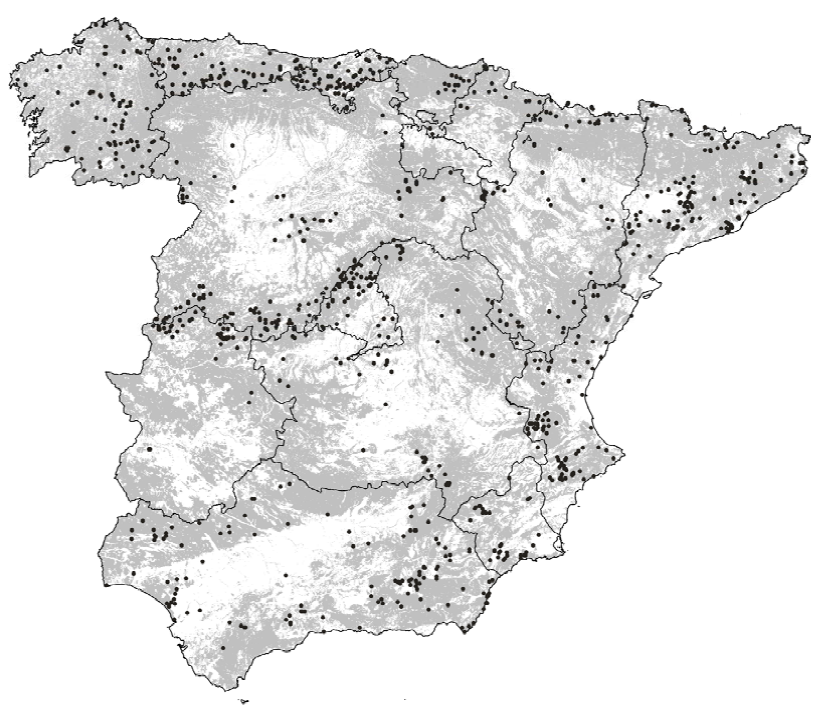

Fig. 1. Location of the 942 profiles established in non-crop areas (grey colour) of peninsular Spain used in the present study.

for the soil profile was more consistent with the vegetation cover according to the Corine Land Cover Map (see below). A further $9 \%$ of the total number of profiles was excluded by this selection. Finally, if two or more profiles shared the same coordinates and vegetation cover (this occurred only in $6 \%$ of the cases) we choose one of them randomly to be included in the final model. Preliminary analyses with different random selections of profiles ensured that the resulting statistical model was unaffected by this selection. This procedure resulted in a final data set containing 942 soil profiles with distinct geographical coordinates, which were finally used in the analyses (Fig. 1).

Selected profiles were overlaid to layers of environmental variables. The choice of the following explanatory variables is based on the most acknowledged factors affecting the SOC stocks (cf. Introduction section), its availability for every profile, and the accessibility of cartographic information for mapping procedures; (1) vegetation cover: land use described in each profile was classified based on the Corine Land Cover Map (Table 1) in order to facilitate the overlaying to the Spanish Forest Map 1:50000 (MFE50) of the period 1997-2006 (Área de Banco de Datos de la Naturaleza, 2011). (2) Soil characteristics: based on geological expert criteria, every soil description, geological class and topoclimatic region were reclassified into three layers of geological information: parent material, texture and consistency (Table 1), in order to facilitate the overlaying to the Geological Spanish Map 1:1 000000 (Instituto Tecnológico Geominero de España, 1994). (3) Elevation and slope: both variables could be overlaid to the digital terrain model of the period 2004-2008, with a spatial resolution of $25 \times 25 \mathrm{~m}$ (Instituto Geográfico Nacional, 2010). (4) Mean annual temperature and total annual precipitation: for each profile coordinate, 
Table 1. Variables used in the model. For both categorical variables, vegetation cover (classified following the Corine Land Cover Map) and soil characteristics (based on geologic expert criteria), number of profiles, mean SOC values and the standard deviation of the mean are indicated. For each of the continuous variables, profile ranges, total map ranges and \% of the total range covered by the profiles are indicated. The mentioned variables are shown in bold.

\begin{tabular}{|c|c|c|c|c|c|c|}
\hline \multicolumn{7}{|c|}{ Variables } \\
\hline Categorical & & & & $\mathrm{N}$ of profiles & Mean SOC & SD \\
\hline \multicolumn{7}{|l|}{ Vegetation cover } \\
\hline & \multirow[t]{5}{*}{ Forest } & Broadleaf & Evergreen & 80 & 6.54 & 1.46 \\
\hline & & & Deciduous & 131 & 11.20 & 1.88 \\
\hline & & & Mixed & 12 & 4.26 & 0.00 \\
\hline & & Conifers & & 215 & 9.46 & 2.13 \\
\hline & & Mixed & & 85 & 9.16 & 1.03 \\
\hline & Shrubland & & & 258 & 9.37 & 4.37 \\
\hline & Grassland & & & 162 & 11.22 & 3.49 \\
\hline \multicolumn{7}{|l|}{ Soil characteristics } \\
\hline & \multirow[t]{2}{*}{ Parent material } & Limestone & & 380 & 8.39 & 2.41 \\
\hline & & Silica & & 562 & 10.50 & 3.59 \\
\hline & \multirow[t]{3}{*}{ Texture } & Sandy & & 453 & 10.46 & 3.49 \\
\hline & & Loam & & 374 & 9.05 & 3.01 \\
\hline & & Clay & & 115 & 8.29 & 2.82 \\
\hline & \multirow[t]{3}{*}{ Consistency } & Firm & & 596 & 10.12 & 3.31 \\
\hline & & Friable & & 161 & 9.71 & 3.38 \\
\hline & & Loose & & 185 & 8.05 & 2.85 \\
\hline Continuous & \multicolumn{3}{|c|}{ Profile range } & Total range & \multicolumn{2}{|c|}{ Covered $\%$} \\
\hline Mean annual temperature & \multicolumn{3}{|c|}{$9.0-18.7^{\circ} \mathrm{C}$} & $-0.2-19.5^{\circ} \mathrm{C}$ & \multicolumn{2}{|c|}{$49.7 \%$} \\
\hline Total annual precipitation & \multicolumn{3}{|c|}{$198-2264 \mathrm{~mm}$} & $0-3182 \mathrm{~mm}$ & \multicolumn{2}{|c|}{$64.9 \%$} \\
\hline Slope & \multicolumn{3}{|c|}{ 0-92\% } & $0-169 \%$ & \multicolumn{2}{|c|}{$54.4 \%$} \\
\hline Elevation & \multicolumn{3}{|c|}{$0-3150 \mathrm{~m}$} & $0-3415 \mathrm{~m}$ & \multicolumn{2}{|c|}{$92.2 \%$} \\
\hline
\end{tabular}

both variables were assigned and overlaid using the Digital Climatic Atlas of the Iberian Peninsula, at $200 \times 200 \mathrm{~m}$ spatial resolution (Ninyerola et al., 2005).

\subsection{Statistical analyses}

Generalized linear models (GLMs) were used to fit SOC stocks to $1 \mathrm{~m}$ depth for the 942 profiles in our data set. Explanatory variables included vegetation cover, parent material, soil texture and consistency, mean annual temperature, total annual precipitation, elevation, slope and the interaction between elevation and mean annual temperature. Preliminary correlation analyses suggested that the only nonindependent variables were elevation and temperature, and therefore we include the corresponding interaction in the model. Moreover, to assure the absence of collinearity in the selected model (see below), variance inflation factors (VIFs) were generated (Heiberger and Holland, 2004), resulting in all VIFs lower than 5, except elevation $(\mathrm{VIF}=9.77)$ and the interaction term $(\mathrm{VIF}=5.01)$. The VIF for these latter terms declined to $<5$ when it was computed on the centred predictor variables, implying that multicollinearity has no adverse effects on the significance or interpretation of the model coefficients.

Starting from the saturated model including all the previous explanatory variables, the least significant term was removed step-wise until no further reduction in Akaike information criterion (AIC) was observed. The AIC of the model we finally selected was 6.57 units lower than the AIC of the second best model. In all models, latitude and longitude were used to model the correlation structure of the errors (Venables and Ripley, 2002) by using generalized least squares (function gls in package nlme, R Foundation for Statistical Computing) and a linear spatial correlation structure, which improved model fit in terms of AIC in all cases ( $\triangle$ AIC $\geq 69.17$ units). Nevertheless, $R^{2}$ and VIFs of the selected model were obtained using the $\mathrm{lm}$ function in $R$.

We used a random subsample of $70 \%$ of the soil profiles to fit the model, while the remaining $30 \%$ was used for model validation. The mean $R^{2}$ presented here corresponds to the average from 1000 repetitions of the previous process, each time using different random subsamples for model fitting and validation. All statistical analyses were conducted using the $R$ package (version 2.14). 


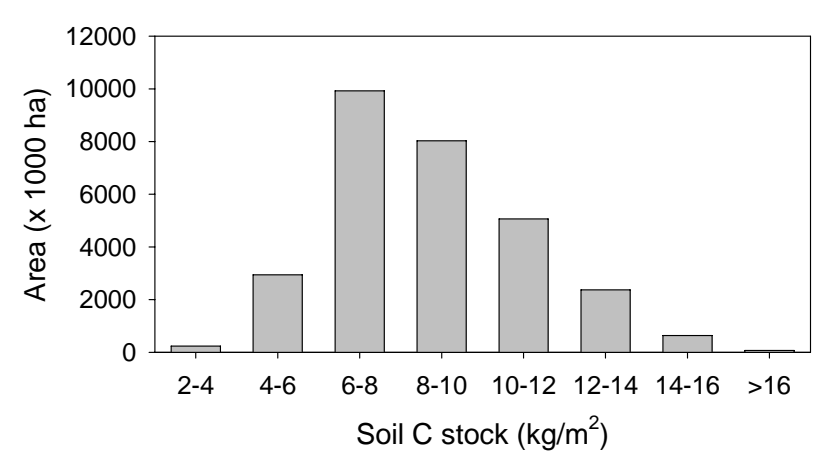

Fig. 2. Distribution histogram of SOC stocks for the covered area.

\subsection{SOC estimation and mapping of the model output}

The coefficients of the fixed part of the statistical model described in the previous section were used to predict SOC for the 7796306 pixels of the Spanish Forest Map $(\sim 200 \times 200 \mathrm{~m}$ spatial resolution). This extrapolation was performed using Miramon (v.7.On). A joint resolution of $0.0018^{\circ}$ was defined according to the characteristics of each original map in order to avoid loss of information and accuracy. The categorical variables were replaced by dummy variables with the values of either 1 or 0 , showing the presence or absence of each category. Finally, the maps of the selected variables in the best model were multiplied by the corresponding regression coefficients to obtain the estimated SOC stock map. Fore each of the continuous variables, covered ranges (by the profiles) and total ranges (of the total extrapolated map) are indicated in Table 1.

\section{Results}

\subsection{SOC model selection and validation}

SOC stocks in the region were strongly related to vegetation cover and climate but also to the interaction of elevation and temperature (Table 2). The $R^{2}$ of the model was 0.659 , and the average $R^{2}$ for the validation sets was 0.654 . The most influential variables were total annual precipitation and mean annual temperature, with a positive and negative effect on the total amount of SOC, respectively (Table 2). Vegetation cover was also important, showing large differences among all categories considered. Mixed broadleaf forests and evergreen woodlands are associated with the lowest SOC values, whereas the highest values corresponded to deciduous broadleaf forests, mixed forests and grasslands (Table 2). The interaction between elevation and temperature was also significant. Graphical outputs indicate that increases in SOC with altitude are mostly related with associated temperature declines while at higher elevations changes in temperature do not affect SOC.

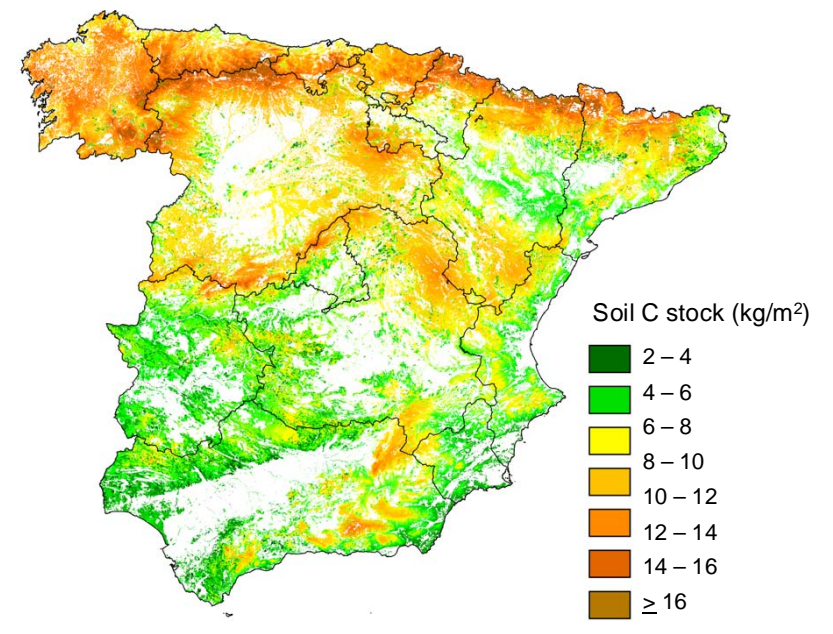

Fig. 3. Map of SOC stocks in natural non crop areas (forests, shrublands and pastures) of peninsular Spain.

\subsection{Amount and distribution of SOC stocks}

The total predicted SOC stock (to $1 \mathrm{~m}$ depth) in Spanish forests, shrublands and grasslands was $2544.4 \mathrm{Tg}$, with a mean value of $8.7 \mathrm{~kg} \mathrm{~m}^{-2} \pm 2.4$ S.D., ranging from 2.3 to $20.4 \mathrm{~kg} \mathrm{~m}^{-2}$ (Fig. 2). Larger stocks were located in the north and northwest parts of peninsular Spain, related to mountainous areas and high precipitation rates (Fig. 3). This Eurosiberian Atlantic zone is characterized by a cold and humid climate associated with deciduous forests dominated by oaks, ash and beech in the northwest, and by conifers (such as firs and Aleppo pines) around the Pyrenees. Large amounts of SOC were also located in the middle Central and Iberian mountain systems, characterized by the presence of deciduous Quercus pyrenaica forests and conifers such as $\mathrm{Pi}$ nus nigra, respectively. The southern Betic mountain system, where different species of pines coexist with evergreen $Q$. ilex forests, also showed high SOC values. Lower stocks corresponded to the Mediterranean lowlands (Fig. 3). The Mediterranean region shows higher temperatures and usually a period of drought during summer, which correspond principally to Maquis shrublands in the east and south and mixed broadleaf forests of Quercus in the west.

\section{Discussion}

\section{Amount and distribution of SOC stocks}

We believe this estimation of SOC in forests, shrublands and grasslands of peninsular Spain to be the first based on the quantitative modelling of the main variables affecting soil $\mathrm{C}$ stocks, including vegetation cover, soil characteristics and climate. The mean value obtained, $8.7 \mathrm{~kg}$ of $\mathrm{SOC} \mathrm{m}^{-2}$, is lower than the mean value for Spain calculated from the IGBP-DIS database, $23.5 \mathrm{~kg} \mathrm{~m}^{-2}$ (Zinke et 
Table 2. Coefficients of the linear model used to test the effects of vegetation cover, elevation, precipitation, temperature and the interaction between elevation and temperature on SOC content (3rd root transformed). For all explanatory factors of the categorical variable vegetation cover, one level was considered the reference (evergreen), the effect for which was incorporated in the model intercept term, and the effect of all other levels was considered relative to the reference. Therefore, considering the coefficient of the intercept as a baseline, the rest of the coefficients indicate the sign and degree of influence in relation to this reference value. Bold values indicate that the correlation coefficient differs significantly from zero $\left({ }^{*} p<0.05,{ }^{* *} p<0.01\right.$, and $\left.{ }^{* * *} p<0.001\right)$.

\begin{tabular}{|c|c|c|c|c|}
\hline & & Coefficient & Std.Error & $t$ value \\
\hline \multicolumn{2}{|l|}{ Intercept (Evergreen) } & 2.2020 & 0.0608 & $36.20^{* * *}$ \\
\hline \multirow[t]{6}{*}{ As factor: } & Deciduous & 0.1582 & 0.0204 & $\mathbf{7 . 7 7}^{* * *}$ \\
\hline & Mixed broadl & -0.2536 & 0.0485 & $-5^{2.23^{* * *}}$ \\
\hline & Conifers & 0.1496 & 0.0185 & $\mathbf{8 . 1 0}^{* * *}$ \\
\hline & Mixed & 0.1606 & 0.0217 & $\mathbf{7 . 3 9}^{* * *}$ \\
\hline & Shrubland & 0.1411 & 0.0179 & $\mathbf{7 . 8 6}^{* * *}$ \\
\hline & Grassland & 0.1580 & 0.0200 & $\mathbf{7 . 8 8}^{* * *}$ \\
\hline Elevation & & 0.0000 & 0.0000 & -1.84 \\
\hline Precipitation & & 0.0000 & 0.0000 & $16.24^{* * *}$ \\
\hline Temperature & & -0.0041 & 0.0004 & $-11.26^{* * *}$ \\
\hline Elevation:Temperature & & 0.0000 & 0.0000 & $4.25^{* * *}$ \\
\hline
\end{tabular}

al., 1998). However, the very different means obtained from other Mediterranean countries (for example, 12.9 for Italy or $6.21 \mathrm{~kg} \mathrm{~m}^{-2}$ for Greece) and the low number of profiles representing the Spanish territory (15) only confirm the need of reassessing large-scale estimates of soil C stocks, as current data sets might not be reliable. The SOC values reported here $\left(3.7-5.6 \mathrm{~kg}\right.$ of SOC m${ }^{-2}$ for the first $20-40 \mathrm{~cm}$ of soil; adapted following Jobbágy and Jackson, 2000, in order to facilitate the comparisons) are within the range presented in the baseline map of Europe (1.3-12.6 $\mathrm{kg} \mathrm{m}^{-2}$ for the first 20$30 \mathrm{~cm}$ of forests' mineral soil; Baritz et al., 2010) and very close to the SOC mean obtained for all the Mediterranean Basin $\left(5.9 \mathrm{~kg} \mathrm{~m}^{-2}\right.$ for the uppermost $30 \mathrm{~cm}$ of mineral soil; Rodeghiero et al., 2011). The total amount of $2544.4 \mathrm{Tg}$ SOC estimated in this study represents $3.3 \%$ of the total SOC of Europe's forests (Jones et al., 2005) and approximately $0.2 \%$ of the total SOC of the world's soils (Batjes, 1996). This quantity represents four times the $\mathrm{C}$ stocks of Spanish forest biomass, estimated at $621 \mathrm{Tg} C$ (Vayreda et al., 2012a).

Although we believe that the SOC estimations presented here are accurate and reliable, as implied by the reasonably high $R^{2}$ obtained in the model validation exercise, the following caveats should be considered. First, the soil profiles used in the study come from a number of sources and were established for different purposes using distinct methodologies. A specific survey conducted using a common experimental design and a standardized protocol would likely improve SOC estimates by reducing unwanted variability among samples. Improving the accuracy and spatial resolution of underlying data layers would certainly result in greater confidence in the distribution of the stocks and its estimates at the local level. Finally, stocks are dynamic and are known to be influenced by land use history (Schulp and
Veldkamp, 2008; Bell and Worrall, 2009). Although including temporal and historical factors pose a challenge to studies at large spatial scales, these factors clearly contribute to the variance in SOC stocks that could not be explained by our model.

There have been two previous attempts to estimate SOC stocks for the whole Iberian Peninsula, conducted by Rodríguez-Murillo (2001) and Chiti et al. (2012). However, these two studies used different methodologies. On the one hand, Rodríguez-Murillo (2001) based his approximation on polygons of $10 \mathrm{~km}^{2}$. He assigned to each polygon the mean SOC of the profiles included in the polygon or the average SOC of the corresponding land use when no profiles were present in the polygon. On the other hand, Chiti et al. (2012) assigned the mean SOC of the profiles included in a forest type-bioclimatic belt. The average SOC stock value $\left(9.4 \mathrm{~kg} \mathrm{Cm}^{-2}\right.$, excluding croplands) obtained by Rodríguez-Murillo (2001) is similar to our estimates $\left(8.7 \mathrm{~kg} \mathrm{C} \mathrm{m}^{-2}\right)$. However, the spatial distribution of the stocks shows striking differences leading to substantial differences at the local scale. For example, SOC stocks proposed by Rodríguez-Murillo (2001) in southern mountain systems such as Sierra Nevada are much lower than ours. Although Chiti et al. (2012) did not map their SOC estimates, the mean value they obtained $\left(6.9 \mathrm{~kg} \mathrm{C} \mathrm{m}^{-2}\right)$ is lower than ours, which could be explained by the absence of grasslands in their calculations. Several reasons support the use of the SOC estimates presented here. First, the extrapolation of data was based on a statistical model that considers several predictors, including discrete and continuous variables, as recommended by numerous studies (Krishnan et al., 2007; Bell and Worrall, 2009; Zhang et al., 2011). Secondly, the spatial data 
layers of vegetation cover and climatic variables used in the present study are more recent and accurate.

There are also some SOC estimates for smaller areas within Spain, which are generally consistent with the estimates presented here (again, adapted to different depths following Jobbágy and Jackson, 2000, in order to facilitate the comparisons). For instance, an average of $3.5 \mathrm{~kg} \mathrm{~m}^{-2}$ (to $50 \mathrm{~cm}$ depth) was found in the Guadix-Baza Basin, an arid Mediterranean area (Díaz-Hernández et al., 2003), which is close to our estimation for the same area (3.9 for the first $40 \mathrm{~cm}$ ); whereas a higher $6.4 \mathrm{~kg} \mathrm{~m}^{-2}$ (to $30 \mathrm{~cm}$ depth) was found in an oak stand in NW Spain (Balboa-Murias et al., 2006), very similar to our approximation (6.3 for the first $30 \mathrm{~cm}$ ). In concordance with other studies on SOC distribution (Romanyà et al., 2007), our results showed that lowland Mediterranean soils contain lower quantities of SOC than Atlantic and mountain soils. Forest deforestation would thus result in greater soil $\mathrm{C}$ losses in wet continental and mountain areas than in semiarid and lowland Mediterranean areas (Romanyà et al., 2007), particularly considering that the spatial patterns of forest biomass in peninsular Spain follow a similar distribution in relation to Atlantic and Mediterranean Spain (Vayreda et al., 2012a).

\section{Factors affecting SOC stocks and expectations for the future}

On the one hand, the main variables influencing the spatial distribution of SOC were climate and vegetation cover, in concordance with similar studies in the region (RodríguezMurillo, 2001; Chiti et al., 2012). However, this result contrasts with the patterns observed for forest biomass stocks, which were mainly determined by forest structural diversity, with a much lower direct effect of climate (Vayreda et al., 2012a). Also, the interaction between elevation and temperature was significant, which could be related to the combination of unfavourable conditions for decomposition and less forest productivity (and litter input) with altitude (Baritz et al., 2010). On the other hand, soil characteristics and slope showed no influence on SOC.

Although different studies (Powers and Schlesinger, 2002; Schulp and Veldkamp, 2008) found a large influence of soil structure and composition (which also vary with elevation) on $\mathrm{C}$ content, they did not include the effects of climate or cover type. In any case, such factors should be considered at more local scales. In the case of Zhang et al. (2011), who reported a significant variation among soil types, these types could be regarded in most cases as a surrogate of cover, more than as soil characteristics in the sense used here.

The influence of climate on soil C stocks could be related to the role of soil microorganisms in SOC stability, as the soil microflora is highly sensitive to moisture (Coûteaux et al., 1991) and decompose organic matter more rapidly with increasing temperature (Knorr et al., 2005). Although the mag- nitude of the relationship between the rate of decomposition and temperature had been controversial (Giardina and Ryan, 2000; Powlson, 2005), later large-scale studies have corroborated the influence of climate on soil C stocks (Bellamy et al., 2005). Therefore, climate change may play an important role in the C loss of forest soils (Bellamy et al., 2005) and special attention should be paid to C stocks in Mediterranean soils (Rodeghiero et al., 2011). The Mediterranean Basin is one of the most prominent worldwide hotspots of climate change (Giorgi, 2006). Most climate models forecast substantial increases in temperature and declines in precipitation (Gao and Giorgi, 2008; Hoerling et al., 2011), which correspond exactly to the most negative combination for SOC storage according to our model. In addition, other indirect effect of climate change could affect SOC reserves. First, recent warming induces the reduction of tree-growth rate and associated C accumulation (Vayreda et al., 2012b). Second, the general rise in fire risk in the region due to current warming (Moriondo et al., 2006) could aggravate the consequences of climate change on SOC of Mediterranean ecosystems (Rodeghiero et al., 2011).

Vegetation cover also showed an important role affecting soil $\mathrm{C}$ reserves. Differences among the types of forest cover, showing the highest SOC mean under broadleaf forests and higher and lower SOC values for conifers and evergreen forests, respectively, were similar to previous calculations (Chiti et al., 2012). In concordance, promoting the development of forests associated to higher SOC values in specific areas could be used to maintain SOC stocks under future climatic conditions. Future land use changes in Spain are difficult to predict due to the importance of socio-economic dynamics and their inherent uncertainty (e.g. although urban intensification is predicted to increase in lowlands, an economic crisis could halt this pattern), but recent patterns reveal likely tendencies in terms of vegetation structure, composition and dynamics. Coastal landscapes are suffering increasing anthropogenic impact (Alados et al., 2004) while afforestation of low productive uplands has occurred in the last century due to rural exodus (Hill et al., 2008). Although these novel forests may be essential for the restoration of associated SOC sinks, their structural and functional attributes (whether it is very flammable vegetation due to a fast recovery, dense conifer forests derived from afforestation, or higher connectivity among wooded stands) could be heavily influenced by climate change and future fire regimes (Pausas and Fernández-Muñoz, 2012). Management of the type of vegetation cover of such novel forests could thus be a key factor in altering the effects of current global changes, favouring future C storage capabilities (Vayreda et al., 2012a).

In conclusion, the SOC estimates presented here provide a baseline to estimate future changes in soil C stocks in peninsular Spain and to assess their vulnerability to key global change drivers. Likewise, they could be used to improve our ability to respond to environmental changes by informing 
land use management schemes aimed at promoting and conserving $\mathrm{C}$ stocks.

Acknowledgements. The present study is an outcome of the research project MONTES-Consolider (CSD2008-00040), funded by the Spanish Ministry of Economy and Competitiveness. The soil profile database involved the participation of CEAM, the Directorate General of Environmental Evaluation and Quality and the BALANGEIS project (INIA, ref. SUM2996-0030-CO2-01). We thank G. Ojeda for his professional advice.

Edited by: D. Obrist

\section{References}

Adger, W. N. and Brown, K.: Land use and the causes of global warming, Wiley, Chichester, 1994.

Alados, C. L., Pueyo, Y., Barrantes, O., Escós, J., Giner, L., and Robles, A. B.: Variations in landscape patterns and vegetation cover between 1957 and 1994 in a semiarid Mediterranean ecosystem, Landsc. Ecol., 19, 543-559, 2004.

Área de Banco de Datos de la Naturaleza: Mapa Forestal de España, Escala 1:50000, Dirección General de Medio Natural y Política Forestal, Ministerio de Medio Ambiente, y Medio Rural y Marino, available at: http://wms.magrama.es/sig/Biodiversidad/ MFE/wms.aspx?, 2011.

Balboa-Murias, M. A., Rojo, A., Alvarez, J. G., and Merino, A.: Carbon and nutrient stocks in mature Quercus robur L. stands in NW Spain, Ann. For. Sci., 63, 557-565, 2006.

Baritz, R., Seufert, G., Montanarella, L., and Ranst, E. V.: Carbon concentrations and stocks in forest soils of Europe, For. Ecol. Manag., 260, 262-277, 2010.

Batjes, N. H.: Total carbon and nitrogen in the soils of the world, Eur. J. Soil Sci., 47, 151-163, 1996.

Bell, M. J. and Worrall, F.: Estimating a region's soil organic carbon baseline: the undervalued role of land-management, Geoderma, 152, 74-84, 2009.

Bellamy, P. H., Loveland, P. J., Bradley, R. I., Lark, R. M., and Kirk, G. J. D.: Carbon losses from all soils across England and Wales 1978-2003, Nature, 437, 245-248, 2005.

Cabidoche, Y.: Contribution à l'étude des sols de haute-montagne, Université des Sciences du Languedoc \& Ecole Nationale Supérieure d'Agronomie de Montpellier, Montpellier, 1979.

Capel Molina, J. J.: El Clima de la Península Ibérica, Ariel, Barcelona, 2000.

Chaplot, V., Bouahom, B., and Valentin, C.: Soil organic carbon stocks in Laos: spatial variations and controlling factors, Glob. Change Biol., 16, 1380-1393, 2009.

Chiti, T., Díaz-Pinés, E., and Rubio, A.: Soil organic carbon stocks of conifers, broadleaf and evergreen broadleaf forests of Spain, Biol. Fertil. Soils, 48, 817-826, 2012.

Coomes, D. A., Allen, R. B., Scott, N. A., Goulding, C., and Beets, P.: Designing systems to monitor carbon stocks in forests and shrublands, For. Ecol. Manag., 164, 89-108, 2002.

Coûteaux, M. M., Mousseau, M., Célerier, M. L., and Bottner, P.: Increased atmospheric $\mathrm{CO}_{2}$ and litter quality: decomposition of sweet chestnut leaf litter with animal food web of different complexity, Oikos, 61, 54-64, 1991.
Davis, A. A., Stolt, M. H., and Compton, J. E.: Spatial distribution of soil carbon in southern New England hardwood forest landscapes, Soil Sci. Soc. Am., 68, 895-903, 2004.

Díaz-Hernández, J. L., Barahona Fernández, E., Linares González, J.: Organic and inorganic carbon in soils of semiarid regions: a case study from the Guadix-Baza basin (Southeast Spain), Geoderma, 114, 65-80, 2003.

Eswaran, H., Van den Berg, E., and Reich, P.: Organic carbon in soils of the world, Soi Sci. Soc. Am. J., 57, 192-194, 1993.

FAO/IIASA/ISRIC/ISSCAS/JRC: Harmonized World Soil Database (version 1.2), FAO and IIASA, Rome and Luxemburg, 2012.

Gao, X. and Giorgi, F.: Increased aridity in the Mediterranean region under greenhouse gas forcing estimated from high resolution simulations with a regional climate model, Glob. Planet. Change, 62, 195-209, 2008.

Giardina, C. P. and Ryan, M. G.: Evidence that decomposition rates of organic carbon in mineral soil do not vary with temperature, Nature, 404, 858-861, 2000.

Giorgi, F.: Climate change hot-spots, Geophys. Res. Lett., 33, L08707, doi:10.1029/2006GL025734, 2006.

Heiberger, R.-M. and Holland, B.: Statistical analysis and data display: An intermediate course with examples in S-Plus, R, and SAS, Springer, 2004.

Hill, J., Stellmes, M., Udelhoven, T., Röder, A., and Sommer, S.: Mediterranean desertification and land degradation, Mapping related land use change syndromes based on satellite observations, Glob. Planet. Change, 64, 146-157, 2008.

Hoerling, M., Eischeid, J., Perlwitz, J., Quan, X., Zhang, T., and Pegion, P.: On the increased frequency of Mediterranean drought, J. Clim., 25, 2146-2161, 2011.

Hontoria, C., Rodríguez-Murillo, J. C., and Saa, A.: Soil organic carbon contents in arid and semiarid regions of Peninsular Spain, in: Sustainable Use and Management of Soils - Arid and Semiarid Regions, edited by: Faz Cano, A., Ortiz silla, R., and Mermut A. R., Catena Verlag, Reiskirchen, 275-280, 2005.

Instituto Geográfico Nacional: Modelo Digital del Terreno MDT25, Ministerio de Fomento, 2010.

Instituto Tecnológico Geominero de España: Mapa Geológico de España a escala 1:1000000 en formato digital, Ministerio de Economía y Competitividad, 1994.

Jobbágy, E. G. and Jackson R. B.: The vertical distribution of soil organic carbon and its relation to climate and vegetation, Ecol. Appl., 10, 423-436, 2000.

Jones, R. J. A., Hiederer, R., Rusco, E., Loveland, P. J. and Montanarella, L.: Estimating organic carbon in the soils of Europe for policy support, Eur. J. Soil Sci., 56, 655-671, 2005.

Knorr, W., Prentice, I. C., House, J. I., and Holland, E. A.: Longterm sensitivity of soil carbon turnover to global warming, Nature, 433, 298-301, 2005.

Krishnan, P., Bourgeon, G., Lo Seen, D., Nair, K. M., Prasanna, R., Srinivas, S., Muthusankar, G., Dufy, L., and Ramesh, B. R.: Organic carbon stock map for soils of southern India: A multifactorial approach, Curr. Sci., 93, 706-710, 2007.

Liebens, J. and VanMolle, M.: Influence of estimation procedure on soil organic carbon stock assessment in Flanders, Belgium, Soil Use Manage., 19, 364-371, 2003.

Martin, M. P., Wattenbach, M., Smith, P., Meersmans, J., Jolivet, C., Boulonne, L., and Arrouays, D.: Spatial distribution of soil 
organic carbon stocks in France, Biogeosciences, 8, 1053-1065, doi:10.5194/bg-8-1053-2011, 2011.

Moriondo, M., Good, P., Durao, R., Bindi, M., Giannakopoulos, C., and Corte-Real, J.: Potential impact of climate change on fire risk in the Mediterranean area, Clim. Res., 31, 85-95, 2006.

Mueller, T. G. and Pierce, F. G.: Soil carbon maps: enhancing spatial estimates with simple terrain attributes at multiple scales, Soil Sci. Soc. Am., 67, 258-267, 2003.

Ninyerola, M., Pons, X., and Roure, J. M.: Atlas Climático Digital de la Península Ibérica. Metodología y aplicaciones en bioclimatología y geobotánica, Universidad Autónoma de Barcelona, Bellaterra, 2005.

Olsson, M.: Monitoring soil organic carbon stock changes for forest land in Sweden - methods and constraints, MISTRA Programme, Swedish University of Agricultural Sciences, Uppsala, 2002.

Pausas, J. G. and Fernández-Muñoz, S.: Fire regime changes in the Western Mediterranean Basin: from fuel-limited to droughtdriven fire regime, Clim. Change, 110, 215-226, 2012.

Powers, J. S. and Schlesinger, W. H.: Relationships between soil carbon distributions and biophysical factors at nested spatial scales in rainforests of north eastern Costa Rica, Geoderma, 109, 165-190, 2002.

Powlson, D. S.: Will soil amplify climate change?, Nature, 433, 204-205, 2005.

Razakamanarivo, R. H., Grinand, C., Razafindrakoto, M. A., Bernoux, M., and Albrecht, A.: Mapping organic carbon stocks in eucalyptus plantations of the central highlands of Madagascar: A multiple regression approach, Geoderma, 162, 335-346, 2011.

Rodeghiero, M., Rubio, A., Díaz-Pinés, E., Romanyà, J., MarañónJiménez, S., Levy, G. J., Fernandez-Getino, A. P., Sebastià, M. T., Karyotis, T., Chiti, T., Sirca, C., Martins, A., Madeira, M., Zhiyanski, M., Gristina, L., and La Mantia, T.: Soil carbon in Mediterranean ecosystems and related management problems, in: Soil Carbon in Sensitive European Ecosystems, edited by: Jandl, R., Rodeghiero, M., Olsson, M., John Wiley \& Sons, Chichester, 175-218, 2011.

Rodríguez-Murillo, J. C.: Organic carbon content under different types of land use and soil in peninsular Spain, Biol. Fertil. Soils, 33, 53-61, 2001.

Romanyà, J., Rovira, P., Duguy, B., Vallejo, R., and Rubio, A.: C sequestration issues in the Mediterranean soils, in: Greenhousegas Budget of Soils under Changing Climate and Land Use (Burnout), edited by: Jandl, R. and Olsson, M., BFW, 15-22, 2007.
Schlesinger, W. H.: Soil respiration and changes in soil carbon stocks, in: Biotic Feedbacks in the Climate System, Will the Warming Feed the Warming?, edited by: Woodwell, G. M. and Mackenzie, F. T., Oxford University Press, New York, 159-168, 1995.

Schulp, C. J. E. and Veldkamp, A.: Long-term landscape-land use interactions as explaining factor for soil organic matter variability in Dutch agricultural landscapes, Geoderma, 146, 457-465, 2008.

Schulze, E. D. and Freibauer, A.: Carbon unlocked from soils, Nature, 437, 205-206, 2005.

Solomon, S., Qin, D., Manning, M., Chen, Z., Marquis, M., Averyt, K. B., Tignor, M., and Miller, H. L.: Climate Change 2007: The Physical Science Basis, Working Group I Contribution to the Fourth Assessment Report of the Intergovernmental Panel on Climate Change, Cambridge University Press, Cambridge, 2007.

Vayreda, J., Gracia, M., Canadell, J. G., and Retana J.: Spatial patterns and Predictors of forest carbon stocks in western Mediterranean, Ecosystems, 15, 1258-1270, 2012a.

Vayreda, J., Martínez-Vilalta, J., Gracia, M., Retana, J.: Recent climate changes interact with stand structure and management to determine changes in tree carbon stocks in Spanish forests, Glob. Change Biol. 18, 1028-1041, 2012b.

Venables, W. N. and Ripley, B. D.: Modern Applied Statistics with S, Springer-Verlag, 2002.

Wiesmeier, M., Barthold, F., Blank, B., and Kögel-Knabner, I: Digital mapping of soil organic matter stocks using Random Forest modeling in a semi-arid steppe ecosystem, Plant Soil, 340, 7-24, 2011.

Zhang, C., Tang, Y., Xu, X., and Kiely, G.: Towards spatial geochemical modelling: Use of geographically weighted regression for mapping soil organic carbon contents in Ireland, Appl. Geochem., 26, 1239-1248, 2011.

Zhou, C., Zhou, Q., and Wang, S.: Estimating and analyzing the spatial distribution of soil organic carbon in China, AMBIO, 32, 6-12, 2003.

Zinke, P. J., Stangenberger, A. G., Post, W. M., Emanuel, W. R., and Olson, J. S.: Global Organic Soil Carbon and Nitrogen. Data set, available at: (http://www.daac.ornl.gov) from Oak Ridge National Laboratory Distributed Active Archive Center, Oak Ridge, 1998. 